\title{
Populismo, emoção e a corrupção da linguagem
}

\section{Jacques A. Wainberg}

Doutor; Pontifícia Universidade Católica do Rio Grande do Sul, Porto Alegre, RS, Brasil

jacqalwa@pucrs.br

\begin{abstract}
Resumo
Este estudo elabora sobre as principais características do discurso populista e analisa os pronunciamentos dos candidatos à presidência da República na eleição de 2018 no Brasil. Trata também da retórica política e de sua tendência à ambiguidade e vaguidade. Para tanto combina vários métodos de pesquisa. Fica clara a tendência oposicionista dos pronunciamentos e o tom emocional dos discursos.
\end{abstract}

Palavras-chave

Populismo. Linguagem. Eleição. Emoção

\section{Introdução}

As ciências duras ou naturais utilizam a matemática como sua linguagem preferencial. Isso acontece porque os números não admitem nem a emoção nem a ambiguidade e a vaguidade. Não é o que acontece com o discurso. No contexto da frase as palavras sempre implicam em algum tipo de viés. A excitação pelo falante de certo sentimento do ouvinte decorre também do seu estilo narrativo e do nível de proximidade existente entre os interlocutores. Resulta o efeito usualmente avaliado em graus ou intensidade. Tal conceito revela o desvio que os vocábulos sofrem desde um ponto considerado como neutro (BOWERS, 1963; p. 345).

Language intensity is most commonly defined as "the quality of language which indicates the degree to which the speaker's attitude toward a concept deviates from neu-trality" (Bowers 1963, 345).

O impacto afetivo de uma manifestação gera certo nível de stress cognitivo no diálogo. Essa tensão depende ainda da credibilidade de quem se manifesta. Quanto maior for o prestígio social do orador (seu grau de poder, status e/ou expertise) maior será o grau de liberdade que ele terá para violar as expectativas linguísticas da audiência (BURGOON, 
1985). Este desvio poderá produzir entre os audientes o efeito persuasivo desejado pela fonte - a modificação comportamental em favor da mensagem evocada.

No campo da política este tipo de cálculo persuasivo está sempre presente. No caso, o que se diz nem sempre almeja enlaçar com a palavra a realidade extralinguística. 0 objetivo prioritário do discurso é o de gerar empatia e induzir o auditório à ação (HAVELOCK, 1963). O ensaísta francês Henry de Montherlant (1895-1972) diz a propósito deste tema que "a política é a arte de capturar, em proveito próprio, a paixão dos outros".

A ambiguidade e a vaguidade permitem que se diga algo com efeito de sentido polissêmico. A imprecisão rende frutos. Cada ouvinte entende coisas distintas do dito e o orador livra-se da obrigação de apresentar provas que sustentem seu argumento. A ambiguidade e a vaguidade retórica acabam superados pela intervenção do ouvinte que dá algum significado ao dito sem utilizar como critério de significação a verificação empírica do verbete (WITTGENSTEIN, 1987). Ambos também tornam dúbios os compromissos assumidos pelo falante sobre temas polêmicos ${ }^{1}$. Por isso mesmo eles são recursos utilizados por negociadores e diplomatas, por exemplo. Certamente, por necessidade de ofício, a prosa judicial, por ser imperativa e afirmativa, evita este tipo de incerteza, algo nem sempre alcançado no texto legislativo mais suscetível às pressões e interesses dos grupos sociais.

George Orwell denunciou tais abusos retóricos em seu famoso texto Politics and the English Language (1946). Ele pondera que embora seja verdade que o pensamento possa perverter a linguagem, também é verdade que as palavras podem adulterar o pensamento. A posição do relativismo linguístico (BEER, 2012) é próxima dessa ideia. Esta corrente de pensamento afirma que a estrutura da língua afeta a cognição do falante. ${ }^{2}$ Tal ponto de vista foi expresso nos escritos de Wilhelm von Humboldt, Franz Boas e Edward Sapir, entre outros autores. Nesta visão as palavras e os conceitos consolidados numa cultura "ajudam a formatar a fiação do cérebro e as mudanças físicas (da pessoa) durante a emoção" (BARRET, 2018; p. 39). Outra formulação (GLADWELL, 2007) afirma a propósito desse tema que fazemos conexões entre pares de ideias que já estão relacionadas em nossa mente. ${ }^{3}$

Uma das passagens mais referidas de Orwell diz que "a linguagem política se destina a fazer com que a mentira soe como verdade e o crime se torne respeitável". Por isso mesmo o autor recusa os eufemismos enganadores (é o caso no Brasil de doação de campanha para propina); o recurso às metáforas (inimiga da originalidade); os ornamentos de linguagem (que inflam o discurso dando-lhe falsa respeitabilidade); a fala permeada por palavras

\footnotetext{
${ }^{1}$ Polemikos significa "guerreiro".

${ }^{2}$ https://www.youtube.com/results?search_query=how+language+shapes+the+way+we+think

${ }^{3}$ Ver a propósito o Implicit Association Test (IAT) em www.implicit.harvard.edu.
} 
desnecessárias; o jargão (como as buzzwords, por exemplo), o clichê e o chavão; a voz passiva (que delega a responsabilidade aos outros) e o estrangeirismo linguístico. Tudo isso funciona como disfarce.

Segundo o ensaísta mexicano Octavio Paz, "quando a sociedade decai a linguagem é a primeira que se torna gangrenada. Por consequência, a crítica social começa com a gramática e o restabelecimento dos significados". (1994). Outros autores seguiram esta mesma trilha crítica. São os casos, por exemplo, de C. S. Lewis $(1943,1945)$, Robert Lane Greene (2011) e Brendan O’Neill (2017). Essa tese foi defendida no Brasil por Zuenir Ventura. ${ }^{4}$

Os ativistas retóricos dizem que a necessária mudança dos hábitos, dos valores e dos costumes sociais é sempre precedida por uma disputa linguística deste tipo. É algo que ocorre na atualidade com a crítica feminista e também com o ativismo de outros movimentos sociais (SOWARDS \& RENEGAR, 2006) vocacionados ao protesto e ao confronto. Por decorrência, nos tempos de crise novos termos surgem e vocábulos desaparecem. A disputa ideológica proposta pela dissidência queer em torno do verbete gênero (HOLMES, 1994) era, em 2018, exemplo deste tipo de encruzilhada semântica (BUTLER, 2002). Outro exemplo é o caso do verbete estagflação. Ele apareceu durante a recessão mundial de 1970.

Por decorrência, a abordagem sincrônica ou descritiva duela com a gramática normativa, a que afirma o valor da regra culta e denuncia como erro os desvios no uso da língua pura ou ideal. Tais inadequações podem ser lexicais, fonéticas, semânticas ou sintáticas. É o que ocorre também com a dissimulação retórica. Por exemplo, a BBC, entre outros veículos de comunicação, não utiliza a palavra terrorismo para descrever atos terroristas sob a justificativa de que o juízo de valor implícito no termo não é unânime entre os comentaristas e analistas. ${ }^{5}$

A incessante chegada de refugiados na Europa provocou uma crise linguística similar. Alguns decidiram associar o fato ao termo invasão. ${ }^{6}$ Outros denominam os recémchegados de migrantes. A Al-Jazira anunciou que iria descrever a ocorrência com o verbete refugiado. ${ }^{7} \mathrm{Na}$ Alemanha utilizam-se agora as palavras flüchtlinge (refugiados) e asylbewerber (asilados) para descrever o fato. Caíram em desuso einwanderer (imigrante) e

\footnotetext{
${ }^{4}$ http://noblat.oglobo.globo.com/geral/noticia/2017/03/palavra-em-crise.html.

${ }^{5}$ https://www.salon.com/2010/02/19/terrorism_19/

${ }^{6}$ Este vocábulo tem sido utilizado pelos simpatizantes do Partido AfD, Alternativa Para a Alemanha.

${ }^{7}$ https://www.lemonde.fr/les-decodeurs/article/2015/08/25/migrant-ou-refugie-quelles-

differences_4736541_4355770.html
} 
gastarbeiter (trabalhador convidado). Na Itália é comum a utilização do verbete migrante em vez de extracomunitário (imigrante ilegal) ou clandestino (imigrante indocumentado). ${ }^{8}$

Em última instância o que está em jogo é o tipo de emoção que cada vocábulo gera na audiência. 0 fato explica porque é comum na literatura crítica a acusação de que a comunicação política é uma prática abusiva, insincera e ardilosa. No centro dos debates políticos e semânticos atuais estão expressões como distribuição de renda e função social. Os opositores do intervencionismo econômico preferem definir esta prática como confisco e roubo. De maneira similar a utilização do vocábulo progressista por grupos de esquerda é polêmica. 0 termo enquadra diferentes tendências ideológicas e personalidades que são por vezes bastante autoritárias, regressivas e até mesmo inibidoras do desenvolvimento. Ocorre que este vocábulo é poderoso porque é um recurso retórico adulador. É um louvor utilizado pelo falante que visa através da lisonja a si e aos seus desmerecer de forma sutil e por via indireta o opositor.

As palavras têm igualmente capacidade de controlar o humor, seja ele individual ou coletivo. Este resultado, o de afetar a alma com o pesar, com o prazer ou com o medo equivale, na visão do sofista Górgias, a do remédio que afeta o corpo.

é preciso também por opinião mostrar aos ouvintes: toda poesia eu considero e denomino um discurso que tem metro: nos que a escutam penetra um calafrio de terror, uma compaixão lacrimosa, um pesar comprazido; e diante das ações e dos corpos alheios, com boa sorte e os reveses, um sofrimento que é próprio, por meio das palavras, a alma sofre. Ora vamos! Que eu mude de um discurso para o outro. (Górgias, Elogio de Helena)

Outros exemplos de vocábulos polissêmicos e ambíguos são interesse nacional, classe média, liberdade, igualdade, estado, a expressão Deus é Amor e agora também golpe de estado, expressão relativizada nas disputas políticas brasileiras. Exemplo similar foram os países comunistas que se autodefiniam ora como República Popular e ora como República Democrática, quando na verdade não eram repúblicas, o regime não era democrático e sua estima social não era popular. Na Alemanha, o Partido Nazista também corrompeu a linguagem apropriando-se da palavra socialista. Seu uso no nome de batismo da agremiação - Partido Nacional Socialista dos Trabalhadores Alemães (Nationalsozialistische Deutsche Arbeiterpartei - NSDAP) - foi feito de forma intencional para atrair e assim afastar os operários do comunismo, uma ideologia que se alastrava no país na década de 1930.

\footnotetext{
${ }^{8}$ https://www.lifegate.com/people/news/eni-accused-floods-nigeria
} 
Também a palavra fascismo, agora popular no Brasil para rotular os eleitores de Jair Bolsonaro, ele próprio e seus aliados, perdeu seu significado original. Nomina agora simplesmente algo indesejável, segundo Orwell. Tornou-se um estandarte utilizado para mobilizar os aglomerados humanos militantes, segundo Simone Weil (2005). Para a autora "nós fazemos estas palavras (como fascismo) significar sucessivamente, ou simultaneamente, qualquer coisa".

A denúncia à terminologia militar é também bastante comum nesta tradição crítica. Ela menciona a desfaçatez deste tipo de vocabulário que tenta tornar a guerra algo respeitável. Para tanto seu vocabulário elabora sobre as regras de engajamento, as que orientam os soldados a dispararem contra seus opositores e inimigos; sobre o efeito colateral (para as vítimas inocentes de um bombardeio); sobre a inteligência (para espionagem); sobre a limpeza étnica (para o genocídio) e sobre a intervenção humanitária (para a invasão armada). ${ }^{9} \mathrm{~A}$ atitude hard do ataque armado é tratada por um vocabulário soft, um disfarce polido permeado por exclamações idealistas (HEDGES, 2011). Por fim, Thomas Merton afirma que a impureza linguística acaba reduzindo a palavra "à ininteligibilidade" (MERTON, 1968, 1981).

0 fato de as posições políticas serem sempre relativas às dos concorrentes, ao contexto e ao tempo também é algo nem sempre considerado por falantes e ouvintes. 0 que num lugar e circunstância é referido como sendo uma posição de esquerda noutro ambiente significará uma posição de direita. É o caso do liberal americano rotulado de conservador na América Latina. Outra dificuldade é a flutuação retórica dos oradores que usam os mesmos verbetes para significar em momentos e circunstâncias distintas coisas.

A Lei de Hotelling ajuda explicar a repentina moderação política de alguns atores e a surpreendente radicalidade de outros, fato que se observa com frequência quando um partido governa e depois passa à oposição, ou ao contrário. Segundo Harold Hotelling (18951973), o agente econômico almeja conquistar sua fração de mercado posicionando-se adequadamente no espaço geográfico para oferecer seus produtos e serviços. 0 cliente, por sua vez, buscará o ponto de venda que lhe for mais conveniente. A tendência é de que o ponto de comércio mais distante do consumidor seja abandonado pela dificuldade de acesso. Naquele lugar extremo o ofertante alcançará somente uma pequena porção da clientela. Quanto mais central ele instalar o seu negócio mais próximo ele estará da maior parte dos fregueses.

\footnotetext{
${ }^{9}$ Uma lista de termos similares pode ser vista em http://www.bilan.ch/garry-littman/english-room/doublespeak-corruptionlanguage-and-min
} 
Tal previsão serve igualmente ao campo das ideias. Quanto mais moderadas elas forem, menor será a distância que a maior parte dos eleitores terá que percorrer para adquirir o bem, no caso, um programa político ou uma ideologia. Este fato explica porque se tem a impressão de que boa parte dos partidos e candidatos envolvidos numa campanha não se distingue já que oferecem soluções semelhantes aos problemas sociais. Na linguagem dos negócios isso equivale a dizer que é racional aos produtores oferecer aos clientes produtos similares (HOTELING, 1929) com pontos de vendas próximos uns dos outros.

Sob o ponto de vista do ofertante a vantagem da localização ótima é o fato de que assim ele mais facilmente conquista o público, muito embora fosse melhor para todos que houvesse uma dispersão maior tanto de farmácias e restaurantes como das ideias e dos partidos. Ocorre que um ator seja ele econômico ou político não se move sem que o competidor se anime a fazê-lo também. Deriva desde fato o teorema do eleitor mediano. Ele diz que um sistema eleitoral majoritário irá selecionar o candidato preferido pelo eleitor médio. Para isso A e B terão que se dirigir a $M$ (ver gráfico).

A ansiosa e fracassada busca por um candidato centrista à presidência da República no Brasil em 2018 é exemplo disso. As áreas em vermelho e azul representam os votantes cativos que A e B pensam ter conquistado seja à esquerda (L) seja à direita (R).

Figura 1: Modelo do eleitor médio

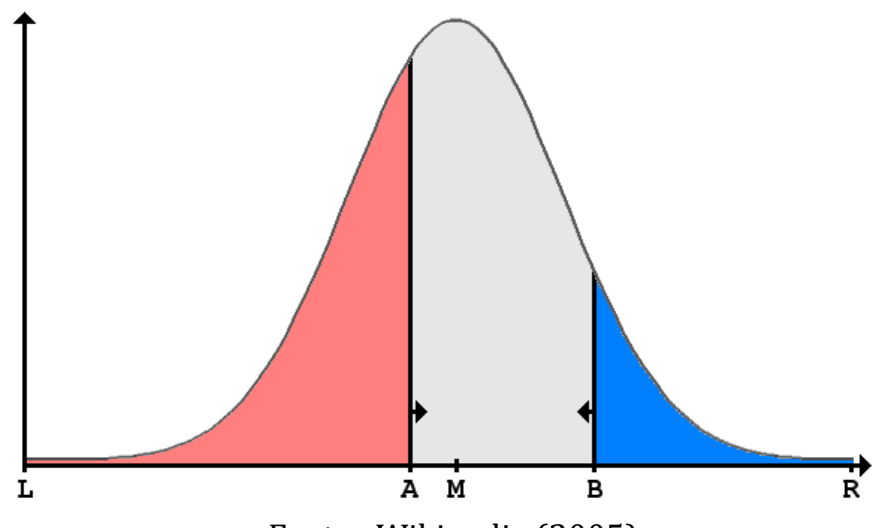

Fonte: Wikipedia (2005).

Naturalmente, tanto no comércio como na política há também a alternativa de um posicionamento estratégico, o que visa simplesmente alcançar certo nicho de mercado. Neste caso, o discurso político é modulado para este fim, algo que acontece geralmente 
através da radicalização retórica, algo usual nos grupos dissidentes vocacionados à luta revolucionária, ou ao contrário, através da moderação súbita de grupos coléricos.

Como mencionado, os que se indispõem à normatização da língua afirmam que o relevante é, simplesmente, a existência dos falantes, seus usos e costumes. Os favoráveis à regra culta da língua, ao contrário, afirmam que no caso de se aceitar qualquer tipo de manifestação será maior a dificuldade de comunicação entre os interlocutores. Eles ponderam também que o duplo sentido dos discursos, algo usual no ambiente político, é prática enganadora.

A verdade é que esta preocupação sobre o abuso das palavras pelos falantes é antiga. John Locke diz em seu celebrado Ensaio Sobre o Entendimento Humano de 1689 (p. 499) que a função clássica da linguagem, a de aproximar as pessoas e as gerações, estava sendo ameaçada necessitando, portanto de reparo. Isso é algo difícil de obter porque, admite Locke, as pessoas não têm e não partilham as mesmas noções sobre a realidade. 0 perigo está no fato de que o mau uso das palavras possa causar graves erros devido à obscuridade que resulta de se aplicar a velhas palavras significados incomuns ou de se introduzir no discurso termos ambíguos.

Entre os inúmeros remédios à corrupção da linguagem e à consequente crise de significado, Locke sugere que não se deve usar uma palavra sem que ela se refira a uma ideia ou a um significado claro. 0 abuso também decorre da inconstância da utilização de certa língua pelas pessoas (p. 479). Ou seja, de nada serve aprender palavras antes que se tenha uma ideia para ser expressa. Além disso, um vocábulo deve ser distinto dos demais.

because the above theories both concern persuasion, the candidate's language choices should have a measurable impact on particular outcomes relevant to the candidate's trustworthiness (HAMILTON, 1997).

A retórica populista como fenômeno linguístico atinge inúmeros países na atualidade. Figuras como Hugo Chaves e Nicolás Maduro na Venezuela, Alberto Fujimori no Peru, Marine Le Pen na França, Evo Morales na Bolívia, Silvio Berlusconi na Itália, Recep Tayyip Erdoğan na Turquia, Vladimir Putin na Rússia, Donald Trump, Bernie Senders e Sarah Palin nos Estados Unidos têm sido incluídos por diferentes comentaristas nas listas de neopopulistas. 0 mesmo ocorre com movimentos e partidos, entre eles a Frente Nacional na França, o Syriza na Grécia, o Tea Party nos Estados Unidos, o UKIP na Grã-Bretanha, o Movimento para o Socialismo da Bolívia, o Movimento 5 Estrelas (M5S) na Itália, o Podemos na Espanha, o Partido da Liberdade da Áustria (FPO) e o Vlaams Blok na Bélgica (rebatizado 
como Vlaams Belang). No Brasil, o tema ressurgiu com a popularidade crescente de Jair Bolsonaro, acusado por muitos comentaristas de ser o mais populista de todos os candidatos à Presidência da República. A verdade é que o populismo não deve ser tratado como uma ideologia, mas como estilo retórico (ASLANIDIS, 2018; STOICA, 2017).

A literatura apresenta como sua principal característica a referência constante ao povo, um underdog descrito como dotado de boas virtudes. Às vezes este significado está implicado na manifestação. Por ser vago e impreciso o povo ora inclui e ora exclui atores e grupos variados. Esta flutuação depende das intenções persuasivas do orador. 0 termo se contrapõe à elite, outro vocábulo incerto, embora julgado como vilão neste tipo de prosa.

A eficiência da retórica populista ocorre por ser uma fala emocional, a que é capaz de fazer o ouvinte associar o discurso a um sentimento que, no caso dos oposicionistas, é negativo (WIRZ, 2018), e positivo quando o orador é o porta-voz e defende a situação. Este fato está documentado na tabela 1. Pode-se observar que os discursos de Juan Perón e Getúlio Vargas são muito mais otimistas que os dos oposicionistas que lutavam em 2018 para conquistar a presidência da República no Brasil. Emoções negativas como o medo, o ressentimento, o desprezo, o insulto e o rancor são mais úteis à política do que as emoções positivas. Elas demandam das massas uma ação empreendedora para a retificação da realidade. 0 discurso populista também é combativo e suscetível a teorias conspiratórias. Geralmente é nacionalista, utilizado à esquerda e à direita com o objetivo de produzir a identificação e a coesão grupal e o confronto com algum ator externo visto como opositor, inimigo ou ameaça (MARQUAT \& MATTHES, 2016). Este tipo de definição operacional para populismo tem sido motivo para uma vasta polêmica e inúmeras abordagens empíricas (ASLANIDIS, 2018; POBLETE, 2015; CANOVAN, 1981).

\section{Estudo}

Resulta que este estudo se insere nesta tradição de investigação e realiza uma análise comparada de discursos dos candidatos à presidência da República no período eleitoral de 2018 no Brasil. Considera para isso cinco características da prosa populista referidas na literatura e apresenta uma definição operacional para cada uma dessas marcas retóricas. Leva em conta na seleção da amostra o fato dos discursos selecionados serem proferidos a plateias de correligionários em momentos políticos similares, os do anúncio da candidatura à Presidência da República em 2018. 
Quadro 1: Quatro marcadores retóricos da prosa populista.

\begin{tabular}{|c|c|}
\hline Categoria & Definição Operacional \\
\hline 1.POVO & $\begin{array}{l}\text { O termo se refere de forma positiva à soberania e/ou à } \\
\text { vontade da maioria da população. Utiliza também expressões } \\
\text { metonímicas: público, cidadãos, pessoas, eleitores, contribuintes, } \\
\text { sociedade, residentes, consumidores, Brasil, brasileiros e } \\
\text { brasileiras, homens e mulheres, nação, trabalhadores e } \\
\text { trabalhadoras, sociedade e população. } 0 \text { ator afirma saber o que o } \\
\text { povo necessita. }\end{array}$ \\
\hline 2.ELITE & $\begin{array}{l}\text { Este termo e expressões metonímicas decorrentes se } \\
\text { referem direta e explicitamente ou indireta e implicitamente e de } \\
\text { forma negativa a grupos e/ou atores que gozam de privilégios } \\
\text { julgados pelo falante como impróprios, ou de status social e poder } \\
\text { político vistos como indevidos e injustos. A elite é julgada como } \\
\text { vilão. }\end{array}$ \\
\hline 3.AMBIGUIDA & $\begin{array}{l}\text { O que é dito pelo falante tem efeito polissêmico no polo } \\
\text { receptor. Ou seja, a expressão por ser vaga tem significado incerto, } \\
\text { pois não remete a uma imagem extralinguística definitiva. }\end{array}$ \\
\hline 4.EMOTIVIDA & $\begin{array}{l}\text { O que é dito pelo falante tem um componente emocional } \\
\text { que pode ser medido e comparado. }\end{array}$ \\
\hline $\begin{array}{l}\text { 5.COMBATIVI } \\
\text { DADE }\end{array}$ & $\begin{array}{l}\text { Predicados ou expressões que indicam a natureza da tarefa } \\
\text { política a ser realizada num futuro próximo. }\end{array}$ \\
\hline
\end{tabular}

Fonte: Elaborado pelo autor (2018).

A frequência da categoria POVO é medida neste estudo através do Writewords e pelo wordcounter360. A ELITE, tida como vilão, está referida de forma explícita nos discursos examinados. A COMBATIVIDADE do falante é considerada através de expressões e predicados utilizados, os que elaboram e revelam a natureza da ação política a ser realizada em caso de vitória do candidato. 0 grau de EMOTIVIDADE dos discursos é medido através do LIWC (Linguistic Inquiry and Word Count). A variável AMBIGUIDADE é medida pelo percentual de metáforas, jargões e eufemismos existentes no discurso, como sugerido por George Orwell. Os dados obtidos são comparados a duas referências consideradas padrão. A primeira são as características do discurso da mídia social contemporânea medidas pelo LIWC. A segunda são as características das manifestações de Juan Perón e Getúlio Vargas, duas personalidades usualmente rotuladas como populistas. 


\section{Resultados}

As análises dos discursos dos candidatos à Presidência da República no momento em que anunciam aceitar concorrer à Presidência da República em 2018 apresentou os seguintes resultados:

Tabela 1: LIWC - Grau de emotividade e racionalidade dos discursos políticos.

\begin{tabular}{|c|c|c|c|c|c|}
\hline & $\begin{array}{c}\text { Racional/lógico } \\
* *\end{array}$ & $\begin{array}{c}\text { Analítico } \\
* * *\end{array}$ & $\begin{array}{c}\text { Emoções } \\
\text { positivas } \\
* * * *\end{array}$ & $\begin{array}{c}\text { Emoções } \\
\text { negativas } \\
* * * * *\end{array}$ & $\begin{array}{c}\text { Tom } \\
\text { Emocional } \\
* * * * * *\end{array}$ \\
\hline LIWC* $^{*}$ & $\mathbf{1 0 . 7 7}$ & $\mathbf{5 5 . 9 2}$ & $\mathbf{4 . 5 7 \%}$ & $\mathbf{2 . 1 0 \%}$ & $\mathbf{4 3 . 3 5}$ \\
\hline Vargas* $^{*}$ & $\mathbf{9 . 0}$ & $\mathbf{8 8 . 8}$ & $\mathbf{4 . 0 \%}$ & $\mathbf{1 . 6 \%}$ & $\mathbf{8 7 . 0}$ \\
\hline Perón* & $\mathbf{1 0 . 5}$ & $\mathbf{7 7 . 0}$ & $\mathbf{4 \%}$ & $\mathbf{1 , 3 \%}$ & $\mathbf{6 5 . 0}$ \\
\hline $\begin{array}{c}\text { 1.Ciro } \\
\text { Gomes }\end{array}$ & 10.0 & 91.0 & $2.7 \%$ & $3.8 \%$ & 18.4 \\
\hline $\begin{array}{c}\text { 2. Jair } \\
\text { Bolsonaro }\end{array}$ & 8,3 & 74,3 & $2.9 \%$ & $1,1 \%$ & 58,5 \\
\hline 3. Lula & 10,3 & 93,2 & $3.5 \%$ & $2.7 \%$ & 43,9 \\
\hline $\begin{array}{c}\text { 4. Marina } \\
\text { Silva }\end{array}$ & 10.6 & 65.6 & $4,1 \%$ & $2,8 \%$ & 38.1 \\
\hline $\begin{array}{c}\text { 5. Geraldo } \\
\text { Alckmin }\end{array}$ & 11,5 & 112,65 & $4,3 \%$ & $1,5 \%$ & 82,75 \\
\hline $\begin{array}{c}\text { 6. } \\
\text { Henrique } \\
\text { Meireles }\end{array}$ & 54,2 & 75,2 & $15,3 \%$ & $0,6 \%$ & 98 \\
\hline $\begin{array}{c}\text { 7. Álvaro } \\
\text { Dias }\end{array}$ & 7,6 & 79,5 & 3,8 & 2,9 & 46,3 \\
\hline $\begin{array}{c}\text { 8. João } \\
\text { Amôedo }\end{array}$ & 10,4 & 83,2 & 4,1 & 2,5 & 53 \\
\hline
\end{tabular}

Fonte: Elaborado pelo autor (2018).

* O padrão LIWC mede as características das comunicações na mídia social. 0 padrão Vargas considera o discurso proferido por Getúlio Vargas no Dia do Trabalho em 1 de maio de 1951. 0 padrão Perón considera o pronunciamento de 10 de outubro de 1945 proferido na Praça de Maio em Buenos Aires.

** 0 indicador Racional/lógico revela o grau no qual as pessoas utilizam as palavras num padrão de pensamento formal, lógico e hierárquico.

*** 0 indicador Analítico se refere ao pensamento formal. 
**** 0 dado revela o percentual das palavras com emoções positivas utilizadas na prédica.

***** 0 dado revela o percentual das palavras com emoções negativas utilizadas na prédica.

****** Quanto maior for o número indicado mais positivo é o tom emocional do pronunciamento. Quanto mais baixo ele for mais negativo é o seu tom emocional. Abaixo de 50 o tom emocional é negativo.

1. 18/03/2017 (https://www.youtube.com/watch?v=oT84VNP9U20) - Ciro Gomes declara que aceita concorrer à presidência pelo PDT.

2. Discurso proferido na conveção do PSL após ser nomeado candidato à Presidência da República. Julho de 2018. https://www.youtube.com/watch?v=H745tHQhWb0

3. Carta aos Brasileiros. https://www.pragmatismopolitico.com.br/2017/11/assim-comolula-bolsonaro-divulga-carta-ao-povo-brasileiro.html

4. https://congressoemfoco.uol.com.br/especial/noticias/marina-lanca-pre-candidaturaa-presidencia-precisamos-dar-sabatico-ao-pt-ao-psdb-e-ao-pmdb/

5. https://www.youtube.com/watch?v=avxRlg6D_7s

6. https://www.youtube.com/watch?v=0b9pbUPDbjQ

7. https://www.youtube.com/watch?v=uYKQuw8e1R4

8. Discurso proferido durante o Fórum da Liberdade em Porto Alegre no dia 10 de abril de 2018. Em https://www.facebook.com/JoaoAmoedoNOVO/videos/n\%C3\%B3s-somos-a-vozda/440477236390446/

Tabela 2: Povo, Elite, Combatividade e Ambiguidade

\begin{tabular}{|c|c|c|c|c|}
\hline Texto & Povo* & Elite** & Combatividade*** & $\begin{array}{l}\text { Grau de } \\
\text { Ambiguidade* }\end{array}$ \\
\hline $\begin{array}{l}\text { 1. Ciro } \\
\text { Gomes }\end{array}$ & $7 \%$ & $\begin{array}{l}\text { Autoridades do } \\
\text { país }\end{array}$ & *Mudar & $1,7 \%$ \\
\hline $\begin{array}{l}\text { 2. Jair } \\
\text { Bolsonaro }\end{array}$ & $1 \%$ & A esquerda & *Reagir & $0,2 \%$ \\
\hline 3. Lula & $2,1 \%$ & $\begin{array}{l}\text { Governo atual } \\
\text { e o velho } \\
\text { modelo }\end{array}$ & *Mudar & $0,8 \%$ \\
\hline $\begin{array}{l}\text { 4. Marina } \\
\text { Silva }\end{array}$ & $3,5 \%$ & Os que roubam & *Agir & $2,2 \%$ \\
\hline $\begin{array}{l}\text { 5. Geraldo } \\
\text { Alckmin }\end{array}$ & $3,5 \%$ & $\begin{array}{l}\text { Plutocratas do } \\
\text { corporativismo }\end{array}$ & $\begin{array}{l}\text { *Mudar } \\
\text { *Consertar } \\
\text { *Reformar }\end{array}$ & $0,4 \%$ \\
\hline $\begin{array}{l}6 . \\
\text { Henrique } \\
\text { Meireles }\end{array}$ & $2,4 \%$ & $\begin{array}{l}\text { Os que não } \\
\text { trabalham pelo } \\
\text { Brasil }\end{array}$ & *Mudar & $0,6 \%$ \\
\hline 7. Alvaro & $2,64 \%$ & Autoridades do & *Refundar a & $2,4 \%$ \\
\hline
\end{tabular}




\begin{tabular}{|c|c|c|c|c|}
\hline Dias & & país & República & \\
\hline $\begin{array}{l}\text { 8. João } \\
\text { Amôedo }\end{array}$ & $1 \%$ & $\begin{array}{l}\text { Os que se } \\
\text { beneficiam do } \\
\text { atual modelo } \\
\text { de Estado }\end{array}$ & $\begin{array}{l}\text { *Transformar } \\
{ }^{*} \text { Consertar }\end{array}$ & $0,6 \%$ \\
\hline
\end{tabular}

Fonte: Elaborado pelo autor (2018).

* Medido por http://www.writewords.org.uk/word_count.asp. \& wordcounter360. 0 percentual equivale à frequência do verbete em relação ao número total de vocábulos. No caso da ambiguidade o percentual é o da presença no discurso de metáforas, eufemismos e jargões.

**Expressão utilizada no discurso e que aponta o principal inimigo dos candidatos.

***Expressão utilizada no discurso para caracterizar a natureza da obra política a ser realizada em caso de vitória.

1. 18/03/2017 (https://www.youtube.com/watch?v=oT84VNP9U20) - Declara que aceita concorrer à presidência pelo PDT.

2. Discurso proferido na convenção do PSL após ser nomeado candidato è Presidência da República. Julho de 2018. https://www.youtube.com/watch?v=H745tHQhWb0

3. Carta aos Brasileiros. https://www.pragmatismopolitico.com.br/2017/11/assim-comolula-bolsonaro-divulga-carta-ao-povo-brasileiro.html

4. https://congressoemfoco.uol.com.br/especial/noticias/marina-lanca-pre-candidaturaa-presidencia-precisamos-dar-sabatico-ao-pt-ao-psdb-e-ao-pmdb/

5. https://www.youtube.com/watch?v=avxRlg6D_7s

6. https://www.youtube.com/watch?v=0b9pbUPDbjQ

7. https://www.youtube.com/watch?v=uYKQuw8e1R4

8. Discurso proferido durante o Fórum da Liberdade em Porto Alegre no dia 10 de abril de 2018. Em https://www.facebook.com/JoaoAmoedoNOVO/videos/n\%C3\%B3s-somos-a-vozda/440477236390446/

\section{Considerações finais}

Como previsto pela Lei de Hotelling todos os candidatos à Presidência da República ofereceram em 2018 ao mercado das ideias um produto de consumo similar, a visão de que o país precisa mudar. Isso implicava em dizer que para votar o eleitor teria forçosamente que levar em conta outro critério que não este - o da insatisfação manifesta pelos candidatos com a situação do país. Todos eles decidiram se posicionar estrategicamente no quadrante oposicionista, local onde pressupunham estar também o eleitor médio brasileiro. Nesse 
sentido, na eleição de 2018 todo eleitor brasileiro era oposicionista e todo candidato era da oposição, mesmo Henrique Meireles, o mais discreto entre eles.

Por decorrência, as emoções negativas, as que servem de vetor ao queixume coletivo, foram exorcizadas por todos os atores, em alguma medida. Ciro Gomes foi o mais pessimista. Meireles, embora se referisse com insistência à necessidade de recuperar a confiança da população no Brasil, foi o mais otimista e positivo. Jair Bolsonaro foi menos negativo em suas ponderações que os três padrões utilizados como parâmetros de comparação. 0 tom de seu discurso superou em positividade as manifestações dos demais candidatos à exceção de Geraldo Alckmin e Henrique Meireles. 0 ex-ministro da Fazenda de Lula mostrou em seu discurso o pensamento dedutivo mais bem elaborado de todos, muito embora o desvio das demais manifestações aos padrões de comparação utilizados tenha sido limitado. Geraldo Alckmin destaca-se no critério Analítico. Neste quesito o maior desvio é o de Marina Silva.

Como exposto, os critérios utilizados neste estudo para classificar a manifestação como populista combina a frequência da referência do falante ao povo, o grau de emoção negativa do discurso (algo que expressa seu antagonismo) e o seu grau de combatividade (algo verificável na acusação específica a um vilão). Por decorrência, destaca-se o candidato Ciro Gomes. Ele é o que mais se referiu ao Povo, especificou um inimigo preferencial (as autoridades do país) e foi o mais negativo (antagonista) entre todos os falantes. Alguns escolheram um bode expiatório vago como o principal culpado pela debacle do Brasil- os que roubam, os plutocratas e os que não trabalham pelo país. João Amoêdo faz um ataque sistêmico - o decadente Estado brasileiro.

Como dito, Henrique Meireles se destaca pelo tom otimista de sua prédica, o que também é verificável no percentual de verbetes positivos de sua fala. Este fato o distingue de todos os demais candidatos que ficaram em geral abaixo das referências de comparação (LIWC, Vargas e Perón). A estrutura lógica utilizada em sua manifestação é outra marca diferencial. Neste quesito Bolsonaro e Álvaro Dias estão no polo oposto. 0 tom analítico da manifestação de Alckmin se destaca enquanto Marina Silva apresentou neste quesito o maior déficit entre todos os candidatos.

Cabe por fim expor o grau de ambiguidade dos discursos analisados. Para tanto se deve avaliar, como proposto, a presença de eufemismos, metáforas e jargões presente nos discursos. Os dados revelam que o discurso menos ambíguo e por decorrência o mais preciso é o de Jair Bolsonaro seguido de perto por Geraldo Alckmin e Henrique Meireles. No polo oposto está o pronunciamento de Álvaro Dias seguido de perto por Marina Silva e Ciro Gomes. 


\section{Financiamento}

Conselho Nacional de Pesquisa (CNPq)

\section{Referências}

ASLANIDIS, PARIS. 'Measuring populist discourse with semantic text analysis: an application on grassroots populist mobilization.' Qual Quant (2018) 52: 1241.

BARRET, Lisa Feldman. How emotions are made. Mariner Books. 2018

BEEK, Wouter. Linguistic Relativism Variants and Misconceptions. Universidade de Amsterdam. Tese de Doutorado. 2012

BOWERS, John Waite. 'Language intensity, social introversion, and attitude change'.Speech Monographs 30: 345-52, 1963

BURGOON, M., \& MILLER, G.R. 'An expectancy interpretation of language and Persuasion.' In H. Giles \& R. Clair (Eds.) The social and psychological contexts of language (pp. 199229). London: Lawrence Erlbaum Associates. 1985

BUTLER, Judith. 'Críticamente subversiva'. In: JIMÉNEZ, Rafael M. Mérida. Sexualidades transgresoras. Una antología de estudios queer. Barcelona: Icária editorial, 2002, p. 5581.

CANOVAN, Margaret. Populism. New York: Harcourt Brace Jovanovuch. 1981

GLADWELL, Malcom. Blink: the power of thinking without thinking. Back Bay Books. 2007

GREENE, Robert Lane. You are what you speak. Delacorte Press; 2011

GÓRGIAS. Elogio de Helena. http://www.consciencia.org/gorgiashumberto.shtml

HAVELOCK, Erick. Preface do Plato. Harvard Univ. Press. 1963

HEDGE, Chris. 'Recognizing the Language of Tyranny:' Thruthdig. 2011

HOLMES, Morgan. 'Re-membering a Queer Body'. Undercurrents. North York, Ontario: Faculty of Environmental Studies, York University: 11-130. Maio 1994

HOTTELING, Harold. 'Stability in Competition.' The Economic Journal. v. 39. n.153 Março de 1929.

JAGERS, Jan \& WALGRAVE, Stefaan. 'Populism as political communication style: an empirical study of political parties' discourse in Belgium.' European Journal of Political Research 46: 319-345, 2007

LEWIS, C. S. The Abolition of Man. 1943

LEWIS, C.S. That Hideous Strength. 1945 
LOCKE, John. An Essay Concerning Human Understanding. 1689

MARQUART, F., \& Matthes, J. 'Campaigning subtle exclusionism: The effects of Right-wing populist positive ads on attitudes toward foreigners in Austria.' Studies in Communication Media, 5(2), 223-239. 2016

MEDIAN Voter Model. In: Wikipedia. 2005. Disponível em:

https://en.wikipedia.org/wiki/File:Median_voter_model.png\#filehistory . Acesso em: 06 set. 2018.

MERTON, Thomas. War and the Crisis of Language. 1968

MERTON, Thomas. Literary Essays. New York: New Directions. 1981

O'NEILL, Brendan. The corruption of political language. 2017

ORWELL, George. Politics and the English Language. 1946

PAZ, Octavio. The Labyrinth of Solitude and Other Writings. Grove Press. 1994

POBLETE, Mario E. 'How to assess populist discourse through three current

approaches.' Journal of Political Ideologies, 20:2, 201-218. 2015

SNYDER, Anna. Language during the Financial Crisis.

SOWARDS, Stacey K. \& RENEGAR, Valeire R. 'Reconceptualizing Rhetorical Activism in Contemporary Feminist Contexts.' The Howard Journal of Communications, 17:5774, 2006

STOICA, Mihnea S. 'Political myths of the popoulist discourse.' Journal for the Study of Religions and Ideologies, vol. 16, issue 46 (Spring 2017): 63-76.

THOMPSON, Caleb. 'Philosophy and Corruption of Language'. Philosophy. V. 67, n. 259, 1992.

WEIL, Simone. 'The power of words'. In Simone Weil. An Anthology. Penguin Books. 2005

WIRZ, Dominique S. 'Persuasion through emotion? An Experimental Test of the EmotionEliciting Nature of Populist Communication.' International Journal of Communication 12, pp. 1114-1138, 2018

WITTGENSTEIN, Ludwig. Tratado Lógico-Filosófico. Lisboa FCG, 1987

\title{
Populism, emotion and the corruption of language
}

\author{
Abstract \\ Abstract: This study describes populist discourse main \\ characteristics and compare speeches given by candidates \\ during the Brazilian election to the Presidency in 2018. It also \\ deals with political rhetoric and its tendency to ambiguity and
}


Populismo, emoção e corrupção da linguagem

vagueness. A number of methodological methods are used to these purposes. It becomes clear the oppositional emotional tone of all candidates.

\section{Keywords}

Populism. Language. Election. Emotion

Recebido em 06/11/2018

Aceito em 19/09/2019 